\title{
EDITORIAL
}

Cómo citar: Vásquez, H. (2021). Editorial. Ciencia, Economía y Negocios, 5(1), 3-4. Doi: https://doi.org/ 10.22206/ceyn.2021.v5i1.pp3-4

A pesar de los estragos económicos y sanitarios que derivaron de la pandemia del COVID-19, el equipo de la revista Ciencia, Economía y Negocios continuó laborando de forma ininterrumpida con el fin mantener un producto de calidad para nuestros suscriptores. Fue así como, a finales de 2020, la revista logró publicar una edición especial enteramente dedicada a estudios relacionados con la pandemia del COVID-19.

El trabajo del equipo editorial ha rendido nuevos frutos durante este año 2021, hemos logrado que la revista se incluyera dentro del catálogo 2.0 del "Sistema Regional de Información en Línea para Revistas Científicas de América Latina, el Caribe, España y Portugal”, también conocido como Latindex, que es un esfuerzo coordinado por la Universidad Nacional Autónoma de México (UNAM), y ofrece contenido publicado por revistas iberoamericanas dentro de una amplia gama de publicaciones científicas. La importancia de pertenecer a este sistema de información académica no solo se basa en la visibilidad y aval que representa, sino en el estándar de calidad que las revistas incluidas deben cumplir, de manera obligatoria, para publicaciones científicas; específicamente, dentro de los 38 criterios de calidad que son exigidos. Nos enorgullece mostrar que la revista Ciencia, Economía y Negocios cumplió con cada uno de ellos (ver aquí).

\section{(ㅇ) (1)}


Para lo que resta de 2021, nuestra intención es continuar ampliando el número de catálogos indexados para la revista. Actualmente, además de Latindex, la revista pertenece al prestigioso catálogo estadounidense del Economic Literature, o EconLit, especializado únicamente en revistas científicas de índole económica y financiera. Otros catálogos a los que pronto estaremos indexando la revista Ciencia, Economía y Negocios incluyen Reserarch Papers in Economics $(R e P E c)$ y Science Direct. Con esto, incrementaremos de forma exponencial el alcance de los artículos publicados en la revista, ya que su visibilidad será a nivel mundial.

A continuación, presentamos un número de trabajos de temática variada, pero de interés actual, relacionados con temas como la sostenibilidad fiscal (Ecuador) y los determinantes de las causas migratorias en los países miembros del Sistema de Integración Centroamericana (SICA); asimismo, artículos vinculados a temas de logística — bastante afectada dentro de la coyuntura actual—, monitoreo de la satisfacción dentro del sector turístico (Ecuador), y los costos sociales relacionados al cierre de las escuelas (República Dominicana), entre otros temas de interés.

Esperamos que trabajos incluidos en este volumen 5, número 1, de la revista Ciencia, Economía y Negocios sean de su interés y a la vez los exhortamos a difundir este esfuerzo con el fin de promover la investigación científica en el campo de las Ciencias Económicas, Empresariales y Financieras. Les recordamos que, además de la versión impresa, esta revista puede ser descargada gratuitamente desde el portal revistas.intec.edu.do y de Google Scholar, y que pueden enviarnos sus trabajos a cen@intec.edu.do.

Harold Vásquez, Ph.D.

Editor, Ciencia, Economía y Negocios Correo-e: harold.vasquez@intec.edu.do 